\title{
XVIII. On a convenient instrument for graduating glass tubes
}

\section{Prof. Bunsen}

To cite this article: Prof. Bunsen (1846) XVIII. On a convenient instrument for graduating glass tubes, Philosophical Magazine Series 3, 29:192, 99-101, DOI: 10.1080/14786444608645586

To link to this article: http://dx.doi.org/10.1080/14786444608645586

曲 Published online: 30 Apr 2009.

Submit your article to this journal ๘

Џll Article views: 2

Q View related articles $\sqsubset$ 
with the electrolyte, its increased excitement causes it to attract and combine with the acid particle nearest it, $a 1$; when these unite the electricity passes to the first basic particle $b 1$, giving it an exalted excitement, which causes it to unite with the acid particle $a 2$, the electric force passing to $b 2$, which becomes excited in turn and takes the particle $a 3$; and so on through the chain till the last particle $b 5$, which, having no further acid to combine with, gives its electricity to the solid conductor which passes along to the battery. If the last particle $b 5$ be a metal that can exist under the circumstances in which it is left, such as copper, silver, \&c., it accumulates upon that electrode as a deposit; if not such as can exist under these circumstances, such as potassium, \&c., it decomposes water and hydrogen is evolved. By this we observe that every equivalent of decomposition will carry an equivalent of acid to the positive electrode. This is exactly what is found by experiment to be the case. That these decompositions and combinations amongst the particles of a salt may produce a current of that salt in the direction of the electric current producing endosmose, can very easily be conceived.

Whether this be the true philosophy of electrolytic action is yet to be further investigated; in the mean time it does not appear inconsistent with any experiments $I$ have yet investigated : but should it be found not to account for electrolytic action under all circumstances, it will be gratifying should it only prove a stepping-stone to a clearer view of the subtile action of this power.

It appears to me that the phænomena observed and described in these papers favour the idea that electricity is but one power or substance, and that that power is identical with chemical affinity. But the further consideration of this point must be deferred till another opportunity.

XVIII. On a convenient Instrument for graduating Glass Tubes, invented by Prof. Bunsen of Marburg*.

TTHIS instrument consists of a mahogany board $\Sigma \frac{1}{2}$ feet 1 long, 7 inches wide, three-quarters of an inch thick. Throughout its centre is a groove 1 inch wide, half an inch deep, arched at bottom, for the reception of tubes. At one part, 5 inches from the end, is placed a brass plate, $1 \frac{1}{5}$ foot long and 2 inches wide, in such a position that when screwed down its edge comes one-half over the groove. It is furnished

* Communicated by the Chemical Society; having been described by Dr. Lyon Playfair January 19, 1846. 
with 4 screw-nuts, passing through a cut portion of the plate, a quarter of an inch long, so as to allow a certain advancement or withdrawal of the plate at pleasure. C and D are two similar plates, placed at the other end of the wooden board, $C$ having the same amount of motion as $\mathrm{B}$, and being precisely similar in every respect. $\mathrm{D}$ is a brass plate of the same di-
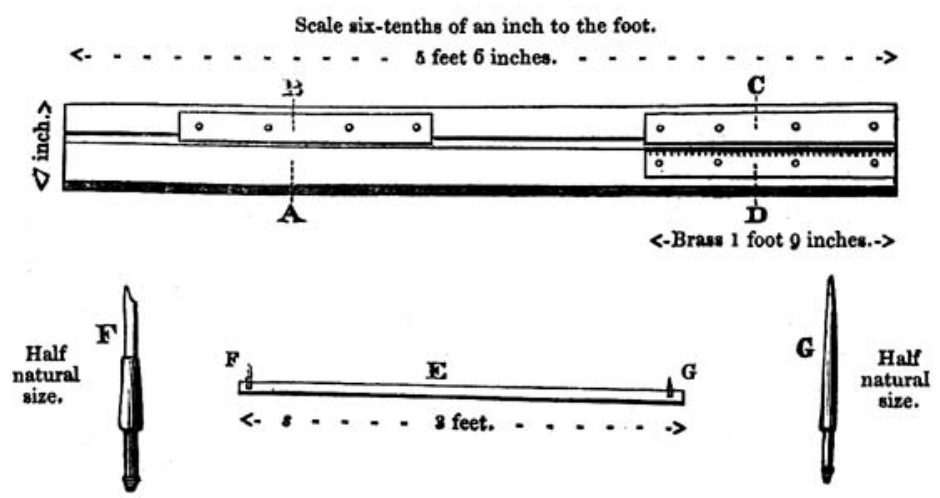

mensions as $\mathrm{B}$ and $\mathrm{C}$, but the screws go through a hole of the same size as themselves into the wood. It is cut, at intervals of five millimetres, into notches, every alternate one being onetwentieth and one-tenth of an inch deep. The instrument is provided with a wooden rod, 3 feet long, 1 inch broad, and half an inch thick, E. This is provided with two steel points, placed by screws at half an inch from either end. One of these, $F$, is in the form of a knife, the other, $G$, of a bradawl. The instrument is furnished with a screw-driver, that these may be removed at pleasure.

When a tube is to be graduated, it is covered with a thin layer of melted wax and turpentine, by means of a camel'shair pencil, and is placed in the groove between $C$ and $D$, which are then screwed down in their places, so as to retain the tube firmly in its position. A standard tube, previously mathematically divided into millimetres (the most convenient division), is now placed in the groove under $B$, which is then screwed upon it. The rod $\mathrm{E}$ is now used, the pointed steel $G$ being put in one of the millimetre marks on the standard tube; the knife-formed steel $F$ is now upon the waxed tube, and is made to make a mark upon it, the length of which is regulated by the distance between the edges of $C$ and $D$. The pointed steel is now removed back one millimetre on the standard tube, and the corresponding mark made on the waxed one; and thus we proceed until the whole of the waxed tube. 
is divided into millimetres. The object of the notches is, that a longer mark may be made at every five millimetres, and a still longer one at every ten, in order to aid the eye in reading. The waxed tube is now removed to a leaden chest, containing pounded fluor spar and sulphuric acid, slightly heated, which etches it more successfully than a solution of hydrofluoric acid. Previously, however, to being etched, it is desirable to figure the number of millimetres at the space of every ten; and this is conveniently done by the steel pointer $G$ after being removed from $E$.

We have thus an accurate measure of length etched upon the tube, which should have been one of pretty uniform calibre. The next point is to determine the true value of each of the divisional marks. This is done by calibrating it throughout all its length with small portions of mercury, say equal in bulk to five grains of water. By this means the relative value of each mark may be determined, and the proportion which it bears to any given standard. The only possible error is in the assumption that the tube is of even calibre between the space occupied by the mercury; but the quantity of this added is so small that any such error becomes quite inappreciable.

The convenience of this graduator is so great, that a long tube may be beautifully divided in the course of a quarter or half an hour. The standard tubes should be made of glass, but the original divisions from which this standard is made may be made on wood or any other material.

XIX. On the Gallo-Nitrate of Silver of Mr. Fox Talbot, and its Action upon Iodized Paper. By Geo. S. Cundell*.

SOME of the properties of this remarkable compound have $\mathcal{D}$ been described by its inventor, and are sufficiently well known; the relations however of its constituent parts, and the means by which the action of the compound may be regulated (some knowledge of which is indispensable to the using it with success), are less generally understood, and have not, so far as I am aware, yet been described.

When solution of the nitrate of silver is applied to iodized paper, a surface is obtained which is extremely sensible to the impressions of light: and, if gallic acid have been added to the solution, the sensibility of the surface will be increased in a remarkable manner.

Preparations however of this kind are subject to a spontaneous and rapid change, independently of light; and, where

* Communicated by the Author. 